\title{
SYNTHESIS AND STUDY OF ATR SPECTRA OF POLYANILINE/GRA NANOCOMPOSITES
}

\author{
O.A. Nunoo, E.K.K. Abavare, R.K. Nkum and K. Singh \\ Department of Physics \\ Kwame Nkrumah University of Science and Technology, Kumasi, Ghana (West Africa)
}

\begin{abstract}
Nano composites are a particular class of materials resulting from combinations of two or more compounds by an appropriate method, which results in materials having unique physicochemical properties and large potential for application in diverse areas. Some of the distinctive properties of polymeric Nano composites can be derived from the successful combination of the uniqueness of the parent constituents into a particular polymer. These composites vary from the pure polymers in respect to some of the physical and chemical properties and hence are useful for many different applications. We synthesized Polyaniline (PANI) in Emeraldine form by chemical oxidation method using Ferric Chloride $\left(\mathrm{FeCl}_{3}\right)$ as a catalyst and Hydrogen peroxide $\left(\mathrm{H}_{2} \mathrm{O}_{2}\right)$, as an oxidant. Simultaneous synthesis of polyaniline (PANI)/GRA Nano composites was also done by the same chemical oxidation method. The characteristic absorption peaks of Attenuated Total Reflectance (ATR) spectra for GRA, PANI and PANI/GRA provide information about the changes in the chemical structure of PANI. ATR spectra also give indication that the incorporation of GRA in the matrix of PANI seems to be effective for the improvement of the physicochemical properties of the Polyaniline.
\end{abstract}

Key words: ATR Spectra, Polyaniline/GRA, Nano composites.

Cite this Article: O.A. Nunoo, E.K.K. Abavare, R.K. Nkum and K. Singh, Synthesis and Study of ATR Spectra of Polyaniline/GRA Nano composites, International Journal of Advanced Research in Engineering and Technology, 10 (4), 2019, pp 4046.

http://iaeme.com/Home/issue/IJARET?Volume=10\&Issue $=4$

\section{INTRODUCTION}

Among the conducting polymers, polyaniline (PANI) has emerged as the material of choice for many applications. PANI is the oldest organic polymer ever synthesized. The first report of polyaniline synthesis was recorded in 1862. Studies carried out in 1910-1911 identified that the molecular sequence involved alternating amine/imine and benzoid/quinoid parts [1]. The wider interest in polyaniline was because of several factors including some research results reporting that PANI exhibited long-standing electrical conductivity following introduction of its stable half- oxidized/half-reduced form called emeraldine base (EB) to a protonic acid [2]. Also Heeger, MacDiarmid and Shirakawa's Nobel Prize winning work that identified the 
physical mechanisms of hole transport in conductive polymer systems [3] brought a new direction in the processing of conducting polymers.

Graphite (GRA) has been extensively studied [4] as it is used to increase the electrical conductivity of polymer matrices. Lei Wang et al. [5] prepared $\mathrm{HClO}_{4}$-doped polyaniline/graphite composites by mechanical ball milling and cold pressing. Many researchers have attempted to convert p-type to n-type conduction in PANI matrix [5-8] by using the fillers forming composites with PANI. The increase in electrical conductivity in polyaniline has also been reported [6] for PANI/graphite nano-composites prepared as pellets and films.

Over the past two decades, interest in polyaniline has increased significantly as a conducting polymer and has shifted from others such as polypyrrole (PPY) because unlike redox doping exhibited by conducting polymers, polyaniline's protonic doping mechanism has advantages over redox doping in other conducting polymers. This has made it a competition to commercially available conducting polymers such as (3, 4ethylenedioxythiophene) (PEDOT) systems in electronic applications [3] (Wagner, 2013). In the present work, an attempt has been made to synthesize and study ATR spectra of PANI and PANI-GRA Nano composites to see the change in the chemical structure of PANI due to GRA in the matrix of PANI.

\section{THEORETICAL ASPECT OF ATR SPECTRA}

In the FTIR spectra of a sample part of the infrared radiation is absorbed by the sample and some part of it transmitted. No two unique molecular structures produce the same infrared spectrum. It is therefore, the resulting infrared spectrum that indicates the uniqueness of the sample with absorption peaks which match with the frequency of vibrations between the bonds of the atoms comprising the material. Also the size of the peaks in the spectrum gives direct indication of the quantity of materials present. The bond positions in the IR spectrum are presented in wave numbers $(\bar{v})$ whose unit is the reciprocal centimeter $\left(\mathrm{cm}^{-1}\right)$ and $v$ is proportional to the energy of vibration.

$$
\Delta \mathrm{E}=\mathrm{hv}=\mathrm{hc} / \lambda=\mathrm{hc} \bar{v}
$$

Each absorption of radiation in the infrared region is quantized and usually appears as a spiky line. The analogy of a chemical bond with two atoms linked through a spring can be used to rationalize several features of the infrared spectroscopy [9]. The approximation to vibration frequency of a bond can be made by the application of Hooke's law. In Hooke's law, two atoms and their connecting bond are treated as a simple harmonic oscillator composed of two masses joined by a spring and frequency of vibration is stated as

$$
\bar{v} \alpha \sqrt{ } \text { (bond strength/mass) }
$$

$$
\text { then } \bar{v}=(1 / 2 \pi \mathrm{c}) \sqrt{ }\left[\mathrm{K} /\left(\mathrm{m}_{1} \mathrm{~m}_{2} / \mathrm{m}_{1}+\mathrm{m}_{2}\right)\right]
$$

Where $\mathrm{m}_{1}$ and $\mathrm{m}_{2}=$ masses of the two atoms, $\bar{v}=$ the vibrational frequency $\left(\mathrm{cm}^{-1}\right), \mathrm{c}=$ velocity of light $(\mathrm{cm} / \mathrm{s}), \mathrm{K}=$ force constant of the bond $($ dyne/cm). The value of $\mathrm{K}$ is approximately $5 \times 10^{5}$ dyne/cm for single bonds and approximately two and three times this value for the double and triple bonds, respectively [9]. Taking $\left(m_{1} m_{2}\right) /\left(m_{1}+m_{2}\right)=\mu$, the reduced mass of the system, $\bar{v}$ can be written as

$$
\bar{v}=(1 / 2 \pi \mathrm{c}) \sqrt{ }(\mathrm{K} / \mu)
$$

Since according to equation (2) $\quad \bar{v} \quad \alpha \sqrt{ } \mathrm{K}$, the vibrational frequency of a bond would increase with the increase in bond strength. As a result, it is expected that $\mathrm{C}=\mathrm{C}$ and $\mathrm{C}=\mathrm{O}$ stretching will have higher frequencies than $\mathrm{C}-\mathrm{C}$ and $\mathrm{C}-\mathrm{O}$ stretching, respectively. 
Also $\quad \bar{v} \quad \alpha \sqrt{ }(1 / \mu)$, the vibrational frequency of a bond would increase with the decrease in the reduced mass of the system. It implies that $\mathrm{C}-\mathrm{H}$ and $\mathrm{O}-\mathrm{H}$ stretching absorptions should appear at higher frequencies than $\mathrm{C}-\mathrm{C}$ and $\mathrm{C}-\mathrm{O}$ stretching frequencies. Similarly, O-H stretching should appear at higher frequency than O-C stretching. Further, as the stretching of the spring requires more energy than to bend it, the stretching absorption of a band always appear at higher energy than the bending absorption of the same band.

\section{METHODOLOGY}

\subsection{Synthesis of Polyaniline (PANI)}

$5 \mathrm{ml}$ of Aniline $(0.054 \mathrm{~mol})$ aniline monomer $\left(\mathrm{C}_{6} \mathrm{H}_{5} \mathrm{NH}\right)$ was added to $100 \mathrm{ml}$ of $1 \mathrm{M}$ Sulphuric Acid $\left(\mathrm{H}_{2} \mathrm{SO}_{4}\right)$, used as a dopant, in a $500 \mathrm{ml}$ flat bottom measuring cylinder with a magnetic stirrer. $2 \mathrm{mg}$ of Ferric Chloride $\left(\mathrm{FeCl}_{3}\right)$, used as a catalyst, was added to $100 \mathrm{ml}$ of distilled water and the mixture added to the first mixture of Aniline and Sulphuric Acid and then continuously stirred using the magnetic stirrer. $100 \mathrm{ml}$ of Hydrogen peroxide, used as an oxidant, was added to the mixture dropwise for about 20 minutes and the final mixture stirred continuously for 6 hours during which the colour changed from green to dark green indicating the formation of the half oxidized Polyaniline (PANI) called Emeraldine salt. The polyaniline salt was then left to stand for 24 hours during which the polyaniline salt was allowed to precipitate. The mixture was then filtered to obtain the dark green coloured polyaniline salt precipitate that was washed several times with distilled water and then finally with ethanol. The Polyaniline (PANI) thus obtained was put in a Petri dish and left to dry in air at room temperature for 24 hours. Again it was dried in oven for 6 hours at $80^{\circ} \mathrm{C}$.

\subsection{Synthesis of Polyaniline-Graphite (PANI-GRA) Composite}

$5 \mathrm{ml}$ of Aniline $(0.054 \mathrm{~mol})$ was mixed with $100 \mathrm{ml}$ of distilled water and $2 \mathrm{mg}$ of Ferric Chloride $\left(\mathrm{FeCl}_{3}\right)$ was mixed with $100 \mathrm{ml}$ of distilled water which was then added to the aniline solution and kept magnetically stirred. Again $5 \mathrm{mg}$ of Graphite Nanoparticles was added to the mix and there after $100 \mathrm{ml}$ of Hydrogen Peroxide $\left(\mathrm{H}_{2} \mathrm{O}_{2}\right)$ was added drop-wise and was kept magnetically stirred. Finally, $100 \mathrm{ml}$ of $1 \mathrm{M}$ Sulphuric Acid was added to this and kept magnetically stirred for about 1 hour during which the dark polyaniline/Graphite Nanocomposite started to precipitate. The mixture was then left to stand for 24 hours and the mixture was filtered to obtain the dark coloured powder form of the Polyaniline/Graphite Nanocomposite. After washing the filtrate several times with distilled water and then finally with ethanol, it was poured into a Petri Dish and left to dry in air at room temperature for 24 hours and also at $80^{\circ} \mathrm{C}$ for 6 hours in an oven.

\section{RESULTS AND DISCUSSION}

The ATR spectra of the PANI and PANI-GRA composites' samples were taken using Perkin Elmer Spectroscope Version 10.03.09 and the peaks that were observed at different frequencies are shown in Table 1.

Table 1

\begin{tabular}{|c|c|c|c|c|c|c|}
\hline S.No & \multicolumn{2}{|c|}{ PANI } & & \multicolumn{2}{c|}{ PANI + GRA } & \\
\hline Peak & $\mathrm{X}\left(\mathrm{cm}^{-1}\right)$ & $\mathrm{Y}(\% \mathrm{~T})$ & & $\mathrm{X}(\mathrm{cm}-1)$ & $\mathrm{Y}(\% \mathrm{~T})$ & \\
\hline 1 & 3844.01 & 80.02 & & 3227.42 & 81.16 & $\begin{array}{c}\text { N-H stretching of } \\
\text { Benzenoid ring }\end{array}$ \\
\hline 2 & 3743.77 & 80.54 & & 3061.79 & 82.27 & \\
\hline 3 & 3221.57 & 76.96 & $\begin{array}{c}\text { N-H stretching of } \\
\text { Benzenoid ring }\end{array}$ & 2112.49 & 90.33 & \\
\hline
\end{tabular}


Synthesis and Study of ATR Spectra of Polyaniline/GRA Nanocomposites

\begin{tabular}{|c|c|c|c|c|c|c|}
\hline 4 & 2938.11 & 76.39 & & 1567.8 & 65.9 & $\begin{array}{c}\mathrm{C}=\mathrm{N} \text { stretching } \\
\text { modes of } \\
\text { Quinoid rings }\end{array}$ \\
\hline 5 & 2351.75 & 78.72 & & 1494.66 & 57.84 & $\begin{array}{l}\text { Are attributed to } \\
\text { benzene ring, } \mathrm{CH} \\
\text { out of plane } \\
\text { vibrations }\end{array}$ \\
\hline 6 & 1565.32 & 68.96 & $\begin{array}{c}\mathrm{C}=\mathrm{N} \text { stretching modes } \\
\text { of } \\
\text { Quinoid rings }\end{array}$ & 1444.53 & 68.92 & $\begin{array}{l}\text { As a result of } \mathrm{C}- \\
\mathrm{C} \text { aromatic ring } \\
\text { stretching of the } \\
\text { benzenoid } \\
\text { diamine unit }\end{array}$ \\
\hline 7 & 1488.02 & 62.92 & $\begin{array}{c}\text { Are attributed to } \\
\text { benzene ring, } \mathrm{CH} \text { out of } \\
\text { plane vibrations }\end{array}$ & 1287.97 & 65.46 & $\begin{array}{l}\text { C-N stretching } \\
\text { modes of } \\
\text { benzenoid rings }\end{array}$ \\
\hline 8 & 1443.06 & 68.25 & $\begin{array}{l}\text { As a result of } \mathrm{C}-\mathrm{C} \\
\text { aromatic ring stretching } \\
\text { of the benzenoid } \\
\text { diamine unit }\end{array}$ & 1245.07 & 68.56 & \\
\hline 9 & 1286.94 & 65.77 & $\begin{array}{l}\mathrm{C}-\mathrm{N} \text { stretching modes } \\
\text { of benzenoid rings }\end{array}$ & 1157.19 & 62.96 & $\begin{array}{c}\text { Combination } \\
\text { modes of } \\
\text { benzenoid and } \\
\text { quinonoid unit }\end{array}$ \\
\hline 10 & 1147.30 & 62.43 & & 822.48 & 67.84 & $\begin{array}{l}\mathrm{C}-\mathrm{H} \text { out of plane } \\
\text { bonding in } \\
\text { benzenoid ring }\end{array}$ \\
\hline 11 & 1075.67 & 63.50 & & 756.26 & 65.51 & \\
\hline 12 & 800.20 & 64.82 & & 740.95 & 65.52 & $\begin{array}{l}\text { C-C, C-H bonding } \\
\text { mode of aromatic } \\
\text { ring }\end{array}$ \\
\hline 13 & 739.53 & 64.47 & & 692.02 & 61.01 & $\begin{array}{l}\mathrm{C}-\mathrm{C}, \mathrm{C}-\mathrm{H} \text { bonding } \\
\text { mode of aromatic } \\
\text { ring }\end{array}$ \\
\hline 14 & 690.84 & 61.73 & & 586.49 & 62.47 & $\begin{array}{l}\mathrm{C}-\mathrm{N}-\mathrm{C} \text { bonding } \\
\text { mode of aromatic } \\
\text { ring }\end{array}$ \\
\hline 15 & 600.79 & 61.62 & & 507.12 & 57.94 & \\
\hline 16 & 505.51 & 57.88 & & 493.28 & 57.66 & \\
\hline 17 & 492.71 & 57.67 & & 409.67 & 59.48 & \\
\hline 18 & 406.38 & 58.91 & & & & \\
\hline
\end{tabular}

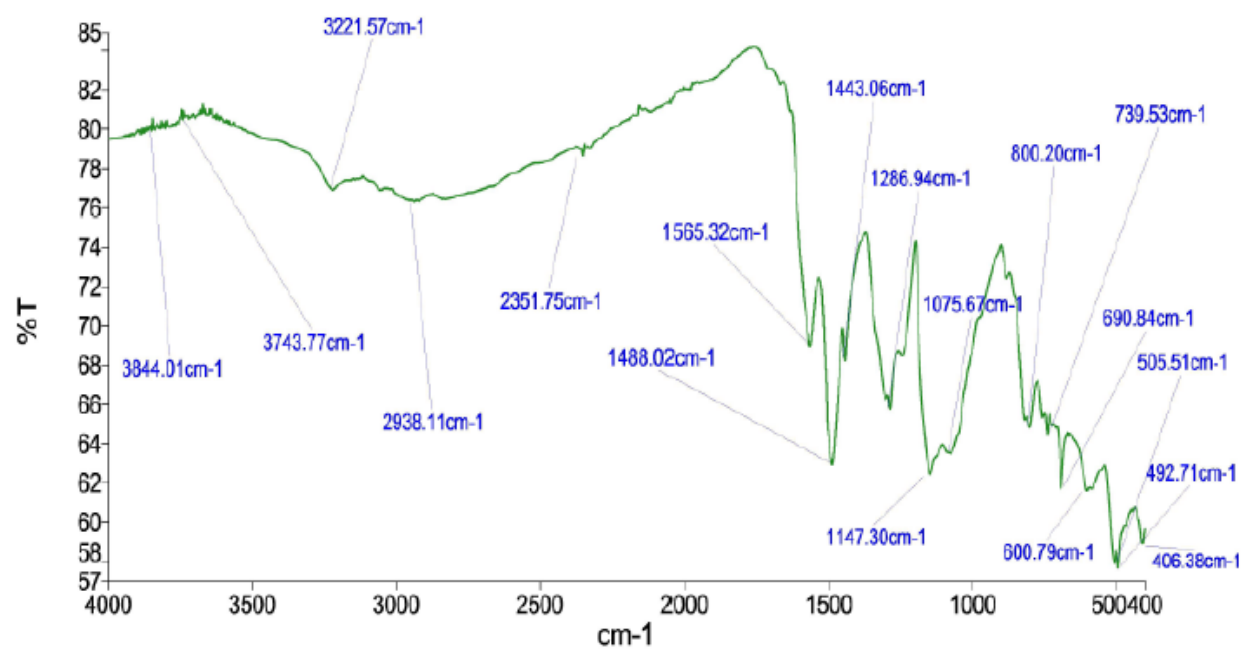

Figure 1 ATR Spectrum of PANI 
O.A. Nunoo, E.K.K. Abavare, R.K. Nkum and K. Singh

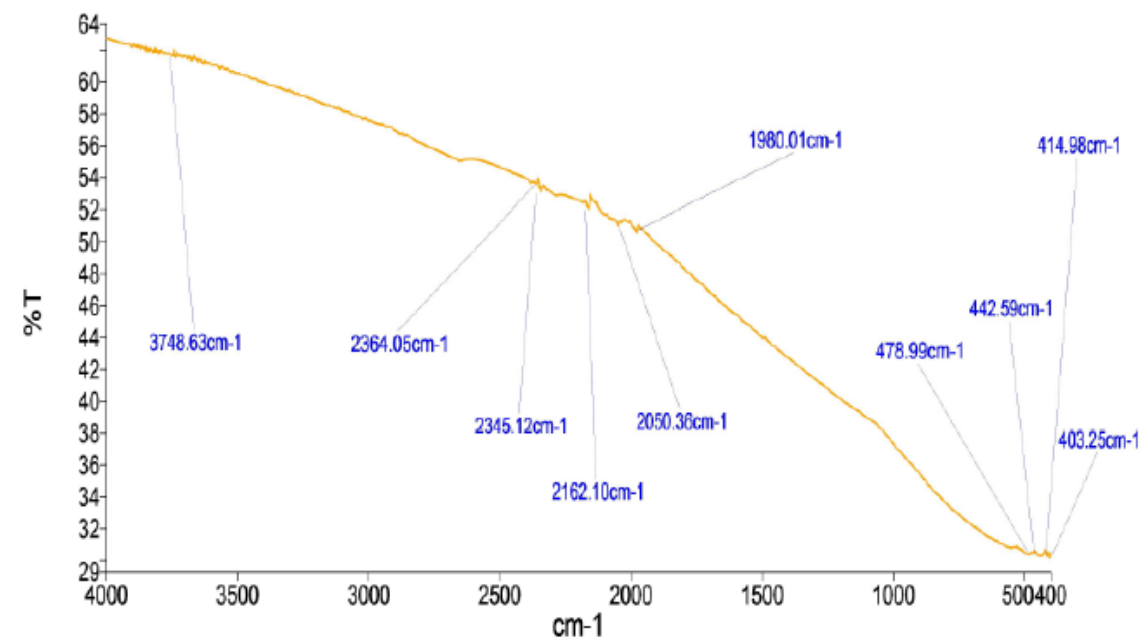

Figure 2 ATR Spectrum of GRA

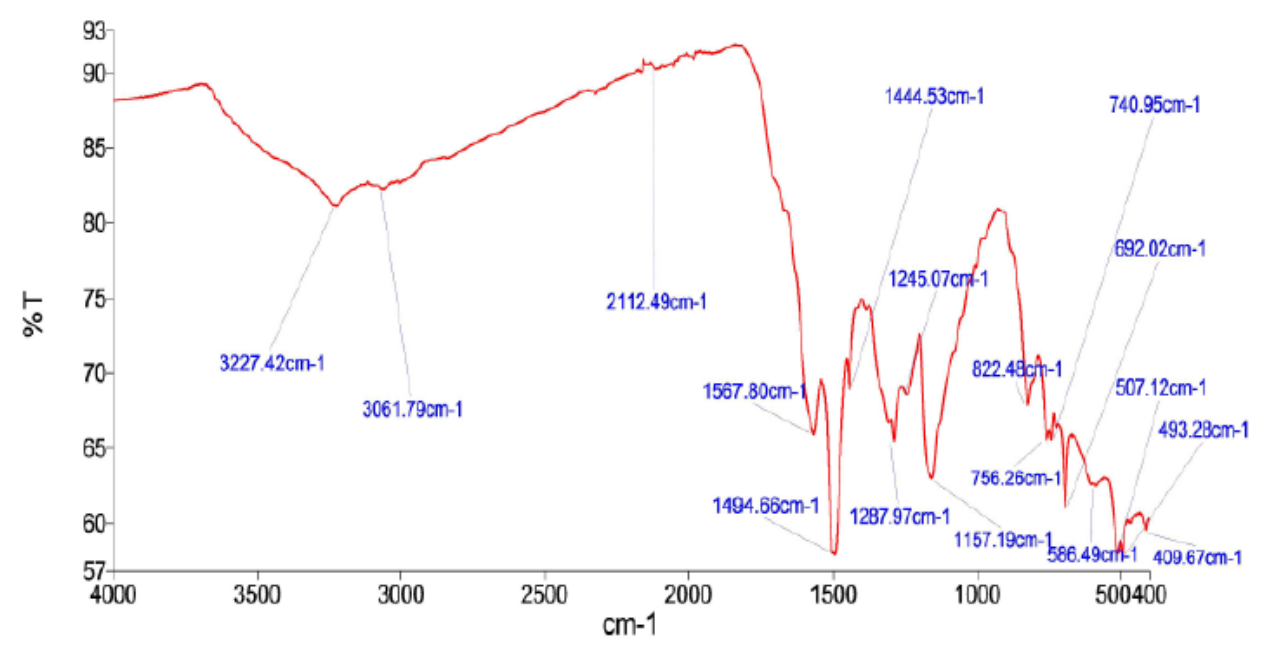

Figure 3 ATR Spectrum of PANI/GRA Composite

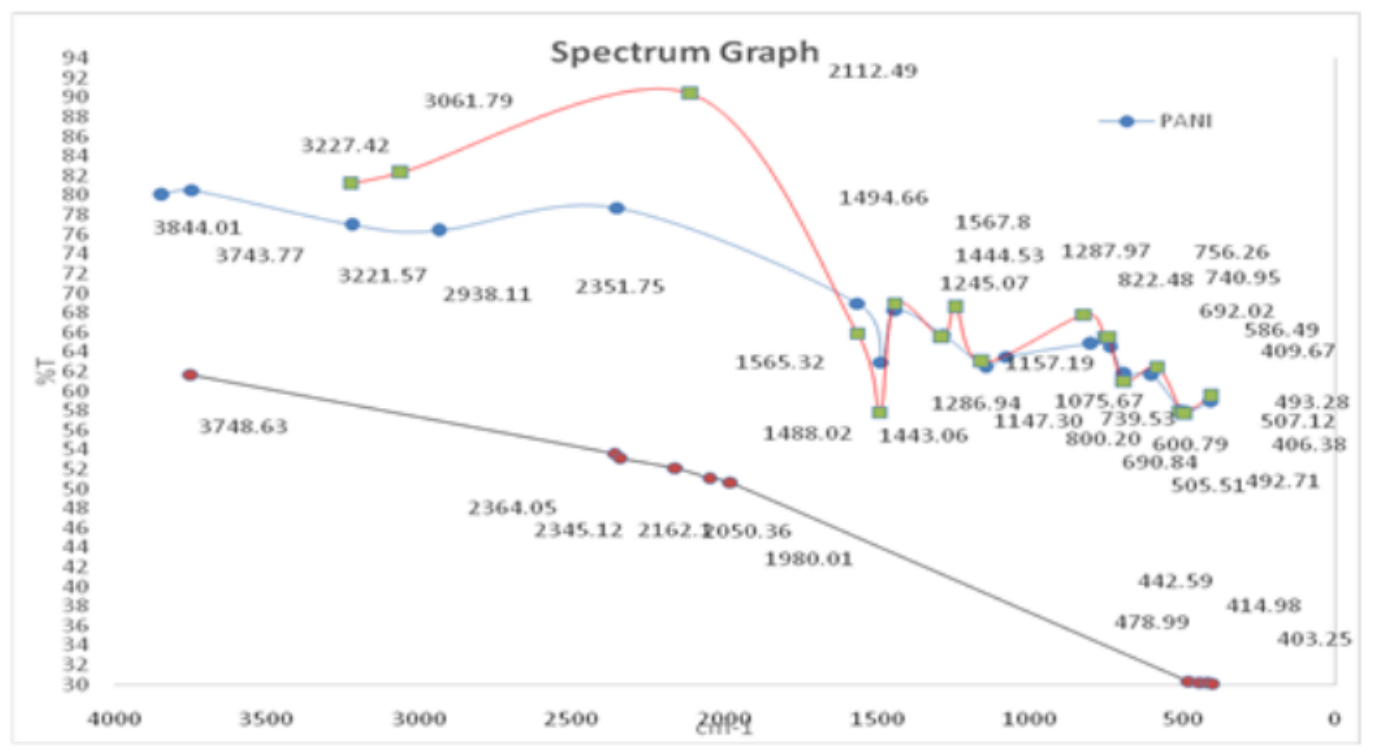

Figure 4 ATR Spectra of GRA, PANI and PANI/GRA Composite 
In ATR spectra (Figures 1 and 3), the peaks at 1565.32 and $1567.8 \mathrm{~cm}^{-1}$ for PANI and PANI-GRA respectively are arising from $\mathrm{C}=\mathrm{N}$ and $\mathrm{C}=\mathrm{C}$ stretching vibration of the quinoid diimine unit $(\mathrm{N}=\mathrm{Q}=\mathrm{N})[10,11]$ while the 1443.06 and $1444.53 \mathrm{~cm}^{-1}$ wave number are as a result of $\mathrm{C}-\mathrm{C}$ aromatic ring stretching of the benzenoid diamine unit $[11,12]$ for PANI and PANI-GRA composite respectively. Also the peaks at $1286.94 \mathrm{~cm}^{-1}$ and $1287.97 \mathrm{~cm}^{-1}$ are coming from C-N stretchings vibration in a polaran structure and that at $1147.30 \mathrm{~cm}^{-1}$ is assigned to aromatic $\mathrm{C}-\mathrm{H}$ in plane bending $[10,12]$. The peak at $822.48 \mathrm{~cm}^{-1}$ in PANI-GRA is as a result of $\mathrm{C}-\mathrm{H}$ out of plane bending vibrations. The peaks at $412.08 \mathrm{~cm}^{-1}$ is coming from free oxihydroxides in the sample.

\section{CONCLUSION}

The attenuated total reflectance (ATR) spectra of samples as shown in Figs. $1-4$ clearly demonstrate specific stretching vibrations in the PANI and PANI-GRA Nano composites. Also the deviation in transmittance in the PANI-GRA composite from PANI evidently illustrate the presence of GRA in the PANI matrix. This provides indication that the incorporation of GRA in the matrix of PANI will be very useful for the improvement of physicochemical properties of PANI.

\section{ACKNOWLEDGEMENTS}

The authors would like to acknowledge the support from the Head of Department of Physics and Mr. N. Daniel of central laboratory, KNUST, Kumasi, Ghana for assisting in the recording of ATR spectra of samples.

\section{REFERENCES}

[1] MacDiarmid A.G Synthetic metals: a novel role for organic polymers, Synthetic Metals Vol. 125 (1), 11-22, 2001.

[2] Okamoto, Y. and Brenner, W., "Polymers", ch.7 in organic semiconductors, 1964, pp125-158

[3] Wagner. M Synthesis, characterization and chemical sensor application of conducting polymers, $\mathrm{PhD}$ (Chemical Engineering) Dissertation. Abo Akademi University, Finland, 2013.

[4] Rastegaralam, M.; Piao, M.; Kim, G.; Dettlaff-Weglikowska, U.; Roth, S. Influence of chemical treatment on the electrical conductivity and thermo power of expanded graphite foils. Phys. Status Solidi C-Curr. Top. Solid State Phys. 2013, 10, 1183-1187.

[5] Wang, L.; Wang, D.; Zhu, G.; Li, J.; Pan, F. Thermoelectric properties of conducting polyaniline/graphite composites. Mater. Lett. 2011, 65, 1086-1088.

[6] Du, Y.; Shen, S.Z.; Yang, W.; Donelson, R.; Cai, K.; Casey, P.S. Simultaneous increase in conductivity and Seebeck coefficient in a polyaniline/graphene Nano sheets thermoelectric Nano composite. Synth. Met. 2012, 161, 2688-2692.

[7] Lu, Y.; Song, Y.; Wang, F. Thermoelectric properties of graphene Nano sheets-modified polyaniline hybrid Nano composites by an in situ chemical polymerization. Mater. Chem. Phys. 2013, 138, 238-244.

[8] Abad, B.; Alda, I.; Diaz-Chao, P.; Kawakami, H.; Almarza, A.; Amantia, D.; Gutierrez, D.; Aubouy, L.; Martin-Gonzalez, M. Improved power factor of polyaniline Nano composites with exfoliated graphene Nano platelets (GNPs). J. Mater. Chem. A 2013, 1, 10450-10457.

[9] G. Naveen Kumar, Y. V. Mohana Reddy and K. Hemachandra Reddy, Mechanical Properties of Nanoiron Particles Reinforced Epoxy/Polyester Nano composites, International Journal of Mechanical Engineering and Technology, 8(3), 2017, pp. 175-184.

[10] Kumar, S., Spectroscopy of Organic Compounds, Guru Nanak Dev University, Amritsar, 2006

[11] Sathiyanarayanan, S., S. Muthkrishnan, and G. Venkatachari, Corrosion protection of steel by polyaniline blended coating. Electrochimica Acta, 2006. 51(28): p. 6313-6319. 
[12] Siny Paul and Sindhu T.K, Optimization of Electric Energy Density in Epoxy-Aluminum Nanocomposite as Dielectric .International Journal of Electrical Engineering \& Technology (IJEET).Volume: 4, Issue: 1, 2013, Pages: 36-45.

[13] Binu P.P, Dr. K.E. George and Dr. M.N. Vinodkumar, Preparation, Mechanical and Thermal Characterization of Isophthalic Polyester-Cloisite15a Nano composite, International Journal of Design and Manufacturing Technology (IJDMT).Volume: 5, Issue: 3, 2014, Pages: 148-154.

[14] Adhikari, A., et al., Electrochemical behavior and anticorrosion properties of modified polyaniline dispersed in polyvinylacetate coating on carbon steel. Electrochimica Acta, 2008. 53(12): p. 4239- 4247.

[15] S.M. Darshan, B. Suresha and B.N. Ravi Kumar, Optimization of Dry Sliding Wear Behaviour of Zirconium Filled Bismaleimide Nanocomposites, International Journal of Mechanical Engineering and Technology (IJMET), Volume 5, Issue 9, September (2014), pp. 62-70

[16] Mubarak Y.A, Abu-Halimeh R and Schubert D, Polypropylene/Styrene-Butadiene-Styrene Nanocomposites: Mechanical Properties, International Journal of Mechanical Engineering and Technology 9(5), 2018, pp. 200-216.

[17] S. Mohamed Ghouse and K. Vijayarekha, Studies on the Surface Tracking Behaviour of Nano Sio2 Filled Silicone Rubber Nanocomposites, International Journal of Mechanical Engineering and Technology, 9(12), 2018, 575-584.

[18] Abdiryim, T., Z. Xiao-Gang, and R. Jamal, Comparative studies of solid-state synthesized polyaniline doped with inorganic acids. Materials Chemistry and Physics, 2005. 90(2-3): p. 367-372. 